\title{
Energy and Entropy Measures of Fuzzy Relations for Data Analysis
}

\author{
Ferdinando Di Martino 1,2,* (D) and Salvatore Sessa ${ }^{1,2}$ (iD \\ 1 Dipartimento di Architettura, Università degli Studi di Napoli Federico II, Via Toledo 402, 80134 Napoli, \\ Italy; sessa@unina.it \\ 2 Centro Interdipartimentale di Ricerca A. Calza Bini, Università degli Studi di Napoli Federico II, \\ Via Toledo 402, 80134 Napoli, Italy \\ * Correspondence: fdimarti@unina.it; Tel.: +39-081-253-8904
}

Received: 18 April 2018; Accepted: 30 May 2018; Published: 31 May 2018

\begin{abstract}
We present a new method for assessing the strength of fuzzy rules with respect to a dataset, based on the measures of the greatest energy and smallest entropy of a fuzzy relation. Considering a fuzzy automaton (relation), in which A is the input fuzzy set and B the output fuzzy set, the fuzzy relation $R_{1}$ with greatest energy provides information about the greatest strength of the input-output, and the fuzzy relation $R_{2}$ with the smallest entropy provides information about uncertainty of the input-output relationship. We consider a new index of the fuzziness of the input-output based on $R_{1}$ and $R_{2}$. In our method, this index is calculated for each pair of input and output fuzzy sets in a fuzzy rule. A threshold value is set in order to choose the most relevant fuzzy rules with respect to the data.
\end{abstract}

Keywords: fuzzy energy; fuzzy entropy; fuzzy rules; fuzzy relations

\section{Introduction}

Let $X=\left\{x_{1}, \ldots, x_{m}\right\}$ be a finite set and $A$ be a fuzzy set of $X$. In [1,2] two categories of fuzziness, measures are defined as energy and entropy (see, e.g., also [3]). The energy measure of the fuzziness of A is given by:

$$
\mathrm{E}(\mathrm{A})=\sum_{\mathrm{i}=1}^{\mathrm{m}} \mathrm{e}\left(\mathrm{A}\left(\mathrm{x}_{\mathrm{i}}\right)\right)
$$

where e: $[0,1] \rightarrow[0,1]$ is a monotonically increasing continuous function, with $\mathrm{e}(0)=0$ and $\mathrm{e}(1)=1$. A particular energy function is given by $e(u)=u$ for any $u \in[0,1]$. In this case, the minimum value of the energy is 0 , and the maximum is given by $E(A)=\operatorname{Card}(X)=m$. The entropy measure of fuzziness of the fuzzy set $\mathrm{A}$ is defined as:

$$
\mathrm{H}(\mathrm{A})=\sum_{\mathrm{i}=1}^{\mathrm{m}} \mathrm{h}\left(\mathrm{A}\left(\mathrm{x}_{\mathrm{i}}\right)\right)
$$

where $\mathrm{h}:[0,1] \rightarrow[0,1]$ is a monotonically increasing continuous function in $\left[0, \frac{1}{2}\right]$ and monotonically decreasing in $\left[\frac{1}{2}, 1\right]$, with $h(0)=h(1)=0$ and $h(u)=h(1-u)$. A simple entropy function is given by $\mathrm{h}(\mathrm{u})=\mathrm{u}$ if $\mathrm{u} \leq \frac{1}{2}$ and $\mathrm{h}(\mathrm{u})=1-\mathrm{u}$ if $\mathrm{u}>\frac{1}{2}$.

Now we consider another finite set, $\mathrm{Y}=\left\{\mathrm{y}_{1}, \ldots, \mathrm{y}_{\mathrm{n}}\right\}$, and a fuzzy relation $\mathrm{R}$ defined by $\mathrm{X} \times \mathrm{Y}$ :

$$
E(R)=\sum_{i=1}^{m} \sum_{j=1}^{n} e\left(R\left(x_{i}, y_{j}\right)\right)
$$

and

$$
\mathrm{H}(\mathrm{R})=\sum_{\mathrm{i}=1}^{\mathrm{m}} \sum_{\mathrm{j}=1}^{\mathrm{n}} \mathrm{h}\left(\mathrm{R}\left(\mathrm{x}_{\mathrm{i}}, \mathrm{y}_{\mathrm{j}}\right)\right)
$$


We now take a continuous t-norm $t$ and a max-t fuzzy relation equation, that is of the following type:

$$
\mathrm{V}_{\mathrm{i}=1}^{\mathrm{m}}\left(\mathrm{R}\left(\mathrm{x}_{\mathrm{i}}, \mathrm{y}_{\mathrm{j}}\right) \mathrm{t} \mathrm{A}\left(\mathrm{x}_{\mathrm{i}}\right)\right)=\mathrm{B}\left(\mathrm{y}_{\mathrm{j}}\right) \quad \mathrm{j}=1, \ldots, \mathrm{n}
$$

where A (resp., B) is a known input (resp., output) fuzzy set, and $\mathrm{R}$ is an $\mathrm{n}$ unknown fuzzy automaton (relation) connecting the inputs-output via fuzzy rules.

Solutions for the fuzzy relation Equation (5) were proposed in [4-6] (see, e.g., [7] if $t=\mathrm{min}$ ). In particular, if we consider the t-norm of Yager [8], the unique greatest fuzzy relation $R_{1}$ is defined as $\mathrm{R}_{1}(\mathrm{x}, \mathrm{y})=\mathrm{A}(\mathrm{x}) \tau \mathrm{B}(\mathrm{y})$, where $\tau:[0,1] \times[0,1] \rightarrow[0,1]$ is given:

$$
\mathrm{a} \tau \mathrm{b}=\left\{\begin{array}{ll}
\left((1-\mathrm{a})^{\mathrm{p}}-(1-\mathrm{b})^{\mathrm{p}}\right)^{1 / \mathrm{p}} & \text { if } \mathrm{a} \geq \mathrm{b} \\
1 & \text { if } \mathrm{a}<\mathrm{b}
\end{array} \quad \mathrm{a}, \mathrm{b} \in[0,1], \mathrm{p} \geq 1\right.
$$

$R_{1}$ is the fuzzy relation having the maximum energy E. Furthermore, in [4,5] the authors propose an algorithm for finding the relation $\mathrm{R}_{2}$, solution of (5) not unique, having the minimum entropy $\mathrm{H}$.

Many works in data and decision analysis present methods to minimize the fuzzy entropy for obtaining the solution with the smallest ambiguity. Some research works, such as [9-17], present fuzzy decision algorithms for classification analysis using minimum fuzzy entropy.

We propose a new method for measuring the strength of fuzzy rules with respect to a set of input-output data, based on the maximum energy and minimum entropy measures.

Our idea is to calculate, for any pair of input and output fuzzy sets, a normalized index of the strength of the rule with respect to the data, which is a function of the maximum energy and minimum entropy. We find the best input-output fuzzy sets pair to be that for which the corresponding index is maximum. If this index is greater or equal to a pre-defined threshold, then we consider the fuzzy rule which is more relevant with respect to the data.

In Section 2, we describe the algorithm presented in $[4,5]$ for calculating the solutions $R_{1}$ and $R_{2}$ of the Equation (5) with the Yager t-norm. In Section 3, our algorithm is presented for evaluating the strength of fuzzy rules with respect to the data. In Section 4, we present the results of two experiments in which we apply our algorithm. Final considerations are shown in Section 5.

\section{Algorithm for Calculating Fuzzy Relations Having the Greatest Energy and Smallest Entropy}

Let $X=\left\{x_{1}, \ldots, x_{m}\right\}, Y=\left\{y_{1}, \ldots, y_{n}\right\}, A$ (resp., B) be a fuzzy set on $X$ (resp., Y). In $[4,5]$ it is proven that $R_{1}$ is the solution of the Equation (5) with maximum energy. For the calculus of $R_{2}$, the following algorithm is developed in $[4,5]$. Let $h$ be defined as in Section 1 . For each $y_{j} \in Y$, we consider $\Gamma\left(y_{j}\right)=\left\{x_{i} \in X: A\left(x_{i}\right) \geq B\left(y_{j}\right)\right\}$. If $B\left(y_{j}\right)>0$, the algorithm finds some $x_{c} \in \Gamma\left(y_{j}\right)$ (generally not unique), such that $A\left(x_{c}\right) \tau B\left(y_{j}\right)$ is not zero and $h\left(A\left(x_{c}\right) \tau B\left(y_{j}\right)\right)$ assumes the minimum value. Then, $R_{2}\left(x_{i}, y_{j}\right)=A\left(x_{i}\right) \tau B\left(y_{j}\right)$ if $x_{i}=x_{c}$ and $R_{2}\left(x_{i}, y_{j}\right)=0$ if $x_{i} \neq x_{c}$. If $B\left(y_{j}\right)=0, R_{2}\left(x_{i}, y_{j}\right)=0$ for each $i=1, \ldots, m$. Below, we show the pseudocodes for calculating $R_{1}$ (Algorithm 1) and $R_{2}$ (Algorithm 2).

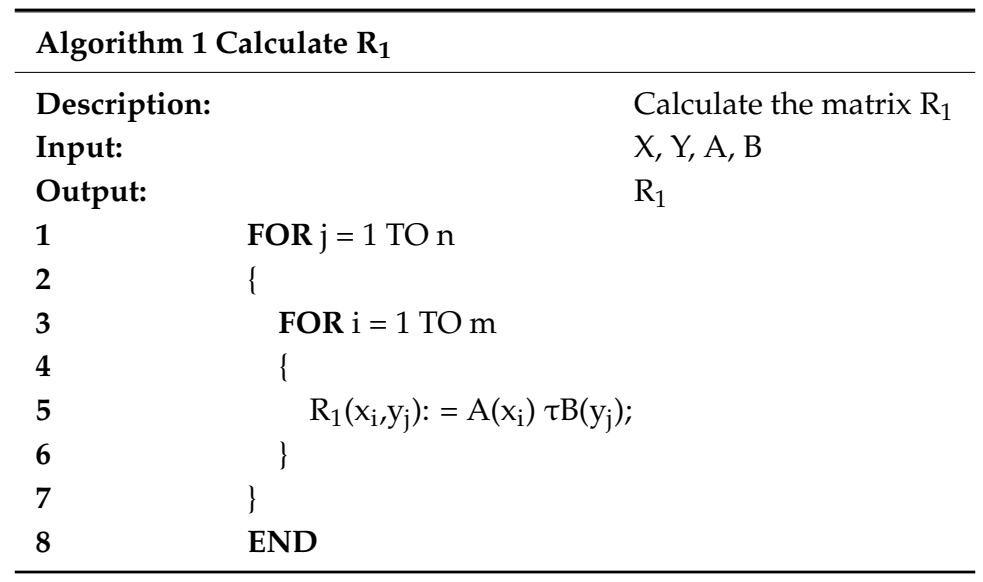




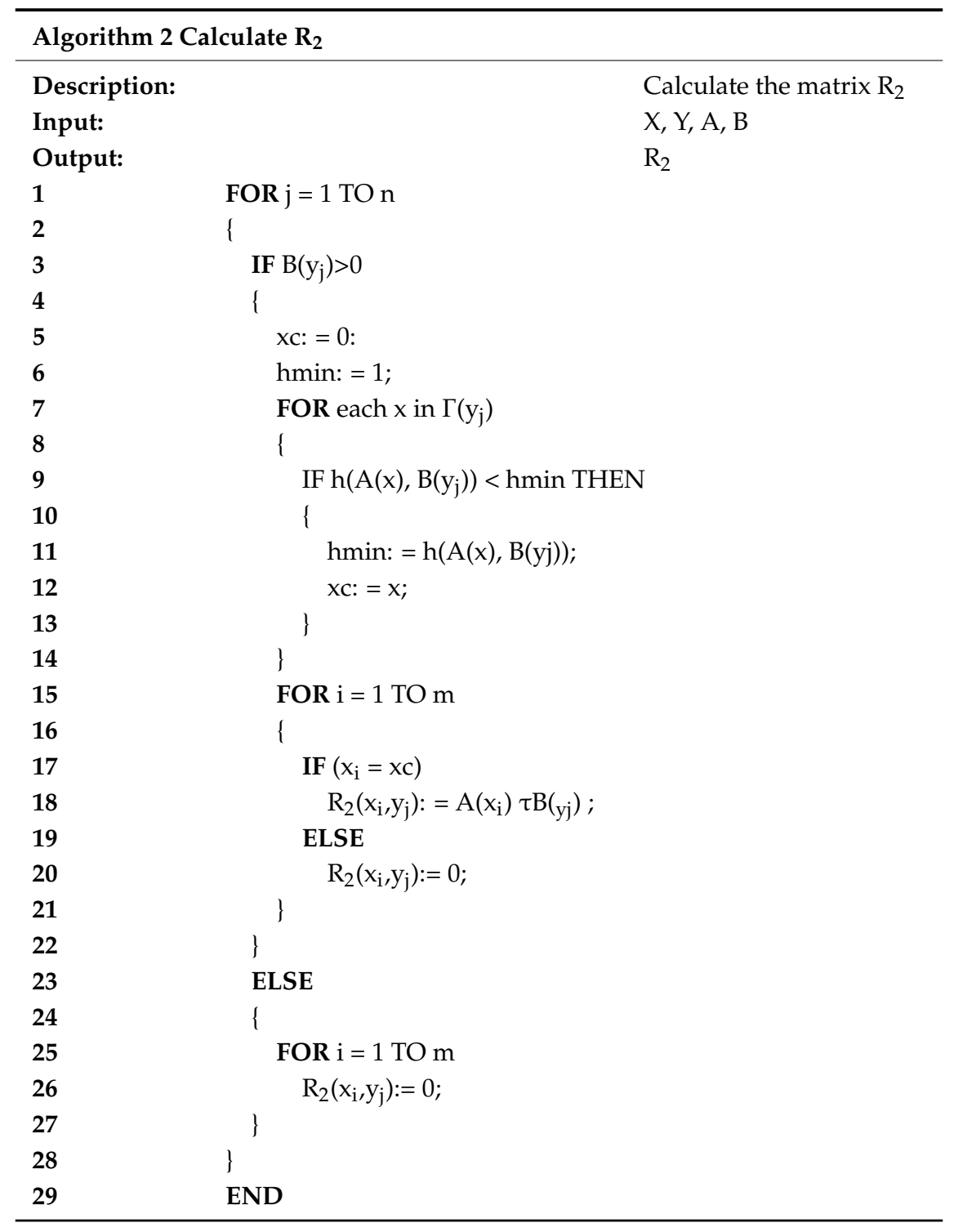

As example, let $X=\left\{x_{1}, x_{2}, x_{3}, x_{4}\right\}, Y=\left\{y_{1}, y_{2}, y_{3}, y_{4}\right\}, A=(0.2,0.3,0.5,0.8)$ and $B=(0.4,0.0,0.6,0.7)$. For $\mathrm{p}=2$ in Formula (6), we obtain that

$$
\mathrm{R}_{1}=\left|\begin{array}{llll}
1.00 & 0.40 & 1.00 & 1.00 \\
1.00 & 0.29 & 1.00 & 1.00 \\
0.67 & 0.13 & 1.00 & 1.00 \\
0.43 & 0.02 & 0.65 & 0.78
\end{array}\right|
$$

For $\mathrm{R}_{2}$, we have $\Gamma\left(\mathrm{y}_{1}\right)=\left\{\mathrm{x}_{3}, \mathrm{x}_{4}\right\}, \Gamma\left(\mathrm{y}_{3}\right)=\left\{\mathrm{x}_{4}\right\}, \Gamma\left(\mathrm{y}_{4}\right)=\left\{\mathrm{x}_{4}\right\}$ and hence $\mathrm{R}_{2}\left(\mathrm{x}_{3}, \mathrm{y}_{1}\right)=0.67$, $\mathrm{R}_{2}\left(\mathrm{x}_{4}, \mathrm{y}_{3}\right)=0.65$ and $\mathrm{R}_{2}\left(\mathrm{x}_{4}, \mathrm{y}_{4}\right)=0.78$. For $\mathrm{B}\left(\mathrm{y}_{2}\right)=0$, we have that $\mathrm{R}_{2}\left(\mathrm{x}_{\mathrm{i}}, \mathrm{y}_{2}\right)=0$ for each $\mathrm{i}=1, \ldots, 4$. Then, the fuzzy relation with minimum entropy is given by:

$$
R_{2}=\left|\begin{array}{llll}
0.00 & 0.00 & 0.00 & 0.00 \\
0.00 & 0.00 & 0.00 & 0.00 \\
0.67 & 0.00 & 0.00 & 0.00 \\
0.00 & 0.00 & 0.65 & 0.78
\end{array}\right|
$$




\section{Evaluating the Strength of the Fuzzy Rules with Respect to the Data}

Our goal is to evaluate the strength of the fuzzy rules considered in a domain's expert with respect to dataset [18]. Transferring its knowledge of the domain, the expert builds a fuzzy partition of q fuzzy sets $\left\{A_{1}, \ldots, A_{q}\right\}$ of the universe of the discourse $U_{x}$ of the input variable $x$, and a fuzzy partition of $s$ fuzzy sets $\left\{B_{1}, \ldots, B_{s}\right\}$ of the universe of the discourse $U_{y}$ of the output variable y. Subsequently, he defines a set of fuzzy rules relating the input and the output variables in the following form:

$$
\text { rk: if } x \text { is } A_{w} \text { Then } y \text { is } B_{z}, w=1, \ldots, q, z=1, \ldots, s
$$

where rk is the kth fuzzy rule of the fuzzy rule set. For instance, let a dataset be composed by $\mathrm{m}$ measures of the input variable $x, X=\left\{x_{1}, \ldots, x_{m}\right\}$, and a dataset composed by $n$ measures of the output variable $y, Y=\left\{y_{1}, \ldots, y_{n}\right\}$. For each rule we extract the pair $\left(A_{w}, B_{z}\right)$ formed by the input and the output fuzzy sets in (7), and we calculate a normalized index based on the maximum energy and minimum entropy. The index represents the strength of the kth fuzzy rule with respect to the data. Let $R$ be the fuzzy automaton (relation) connecting $A_{w}$ and $B_{z}$ by means of Equation (5) with the Yager $t$-norm. Let $R_{1 w z}$ and $R_{2 w z}$ serve as the solutions of (5), with maximum energy and minimum entropy calculated using the algorithms of Section 2. The index of strength for the pair $\left(\mathrm{A}_{\mathrm{W}}, \mathrm{B}_{\mathrm{Z}}\right)$ is defined [4] as:

$$
I_{w z}=\frac{E\left(R_{1 w z}\right)-H\left(R_{2 w z}\right)}{m \cdot n}
$$

For $\mathrm{I}_{\mathrm{wz}}=1$, we obtain $\mathrm{E}\left(\mathrm{R}_{1 \mathrm{wz}}\right)=\mathrm{n} \cdot \mathrm{m}$ and $\mathrm{H}\left(\mathrm{R}_{2 \mathrm{wz}}\right)=0$. If $\mathrm{I}_{\mathrm{wz}}$ is greater or equal to a pre-defined threshold, then the fuzzy rule is confirmed by the data. In Figure 1, this process is schematized.

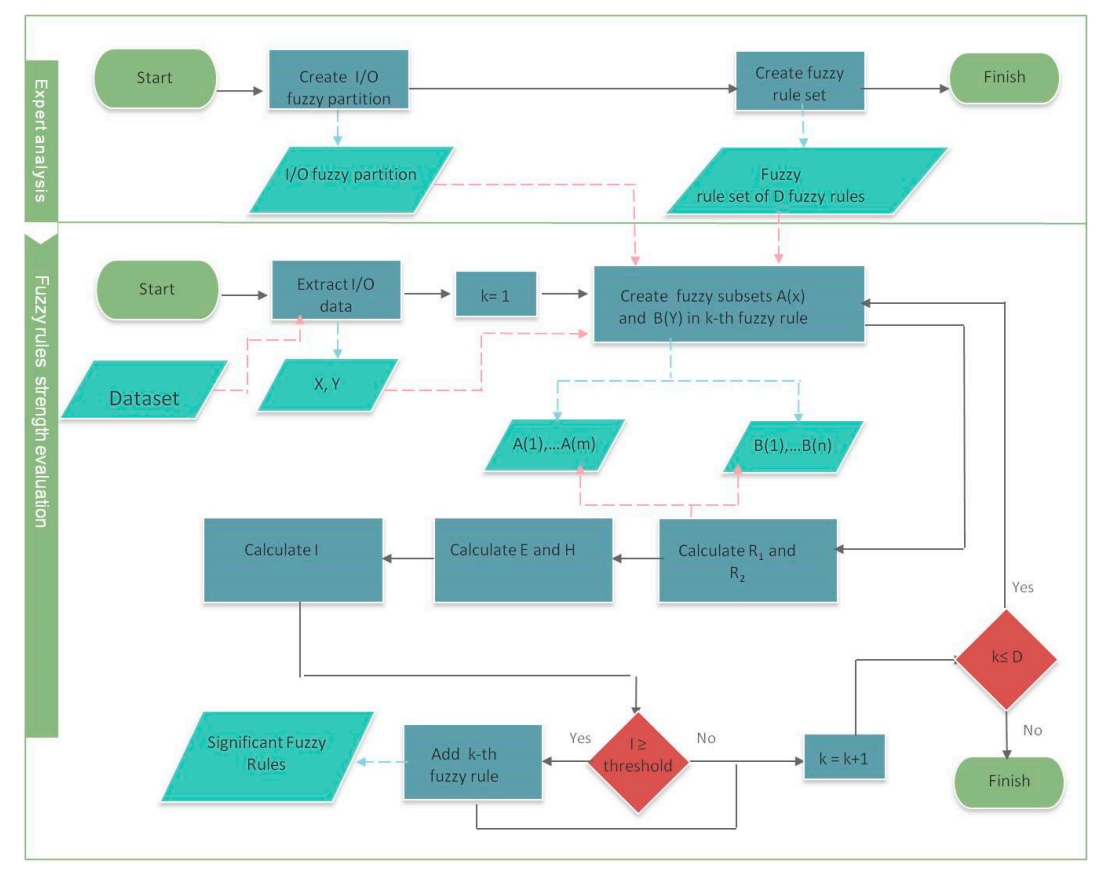

Figure 1. Schema of the process.

The continuous black arrows are related to two processes: the red arrows symbolize the use of data in input and the black arrows symbolize the use of data in output.

In the first phase, the expert creates the fuzzy partition for $U_{x}$ and $U_{y}$ and creates the fuzzy rule set. Then, the expert analyzes each fuzzy rule with respect to a set of data. For the input-output pair $\left(A_{w}, B_{z}\right), A_{w}\left(x_{1}\right), \ldots, A_{w}\left(x_{m}\right), B_{z}\left(y_{1}\right), \ldots, B_{z}\left(y_{n}\right)$, the fuzzy relations $R_{1}$ and $R_{2}$, the Energy $E$, the Entropy $\mathrm{H}$, and the index I are calculated. If the index I is greater or equal to a prefixed threshold, 
then the rule is considered to be significant to the fuzzy rule set with respect to the input/output data. We can generalize this model to the case in which two or more input variables are considered. The generalized form of a fuzzy rule is given by the form:

$$
\text { rk: if }\left(x_{1} \text { is } A_{w 1}^{(1)}\right) \text { and }\left(x_{2} \text { is } A_{w 2}^{(2)}\right) \text { and } \ldots \text { and }\left(x_{v} \text { is } A_{w v}^{(v)}\right) \text { then } y \text { is } B_{z}
$$

where $A_{w l}^{(1)}, 1=1, \ldots, v$, is a fuzzy set of the fuzzy partition of the universe of the discourse of the input variable.

For each pair $\left(\mathrm{A}_{\mathrm{w} 1}^{(1)}, \mathrm{B}_{\mathrm{z}}\right), \ldots,\left(\mathrm{A}_{\mathrm{wV}}^{(\mathrm{v})}, \mathrm{B}_{\mathrm{z}}\right)$, we calculate the corresponding indices $\mathrm{I}_{\mathrm{w}_{\mathrm{Z}} \mathrm{Z}}^{(1)}$ for $\mathrm{l}=1, \ldots, \mathrm{v}$ and assign a measure of strength of the fuzzy rule with respect to the data given by:

$$
\mathrm{I}_{\mathrm{k}}=\min _{\mathrm{l}=1, \ldots, \mathrm{V}} \mathrm{I}_{\mathrm{W}_{\mathrm{l}} \mathrm{Z}}^{(1)}
$$

Below we show the pseudocode of the algorithm (Algorithm 3).

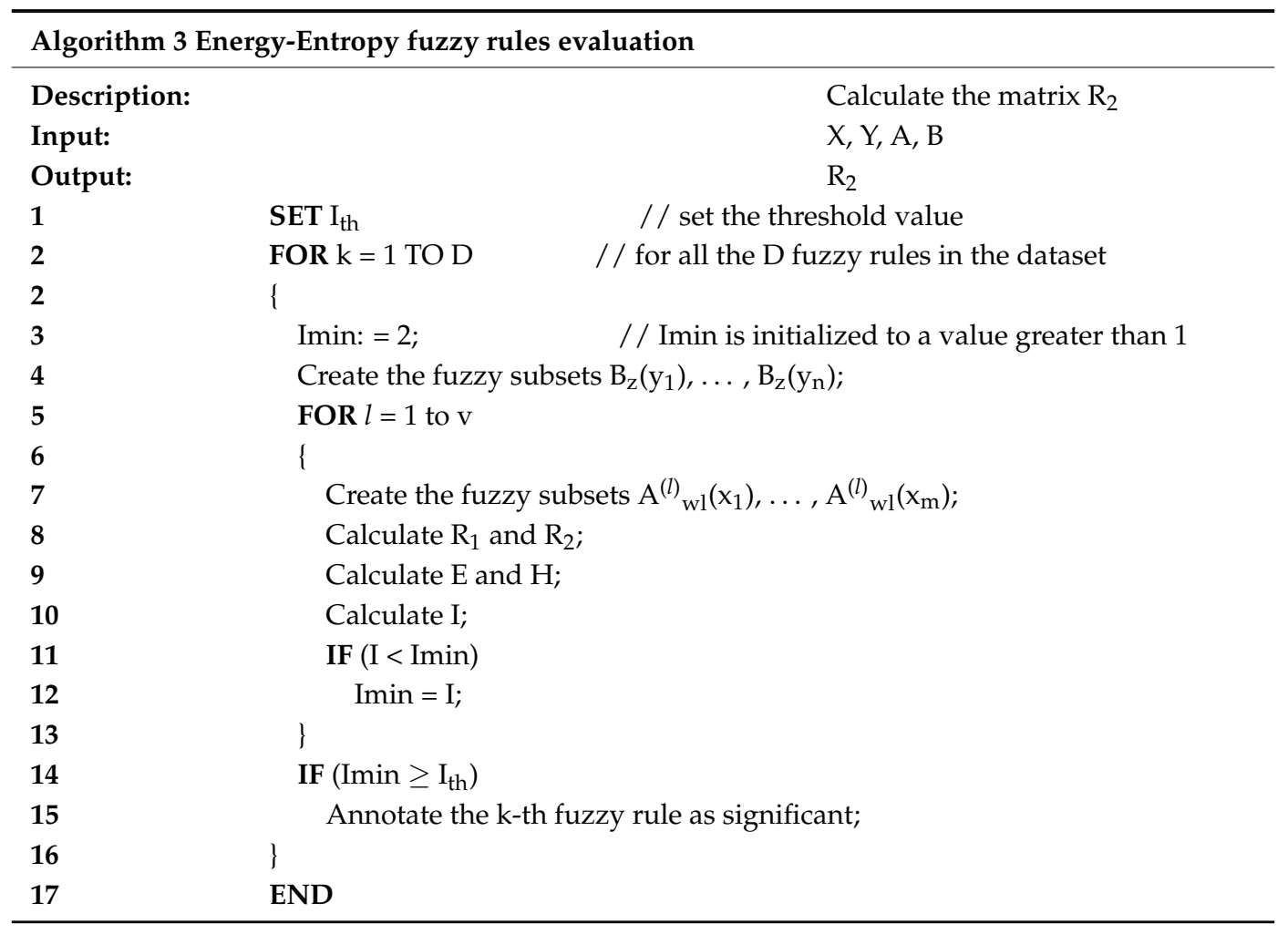

The threshold value $I_{\text {th }}$ can be settled by the expert by using an opportune calibration. This calibration can be obtained by testing the algorithm applied on a sample dataset for which the expert can evaluate the strength of fuzzy rules with respect to the data. In Section 4, we present some results obtained by using various datasets. The first experiment is used for calibrating the threshold value $\mathrm{I}_{\mathrm{th}}$. Obviously the computational time is polynomial, being given by $\mathrm{O}(\mathrm{n} \cdot \mathrm{m} \cdot \mathrm{v})$.

\section{Test Results}

Here we use $\mathrm{e}(\mathrm{u})=\mathrm{u}$ for $\mathrm{u} \in[0,1]$ and, in accordance with [2,3], the following fuzzy entropy:

$$
\mathrm{h}(\mathrm{u})=-\mathrm{u} \cdot \log _{2}(\mathrm{u})-(1-\mathrm{u}) \cdot \log _{2}(1-\mathrm{u}) \quad \mathrm{u} \in[0,1]
$$

and the Equation (5) with the Yager t-norm. 
Our tests are applied to datasets extracted from the open data of the city of Naples (Italy) (www.opendata.comune.napoli.it/) and from database of the $15^{\circ}$ census population performed during 2011 on the Italian territory by the ISTAT (Italian Statistical National Institute), available at http:/ / dati-censimentopopolazione.istat.it. For brevity, we show the results obtained in two experiments.

The city of Naples is partitioned into 10 municipalities. In turn, each municipality includes a set of districts, as listed in Table 1.

Table 1. Municipalities of the city of Naples and their districts.

\begin{tabular}{cc}
\hline Municipality Number & Districts \\
\hline 1 & Chiaia, Posillipo, S.Ferdinando \\
2 & Avvocata, Montecalvario, Porto, S.Giuseppe, Pendino, Mercato \\
3 & Stella, S.Carlo all'Arena \\
4 & Vicaria, S.Lorenzo, Poggioreale \\
5 & Vomero, Arenella \\
6 & Ponticelli, Barra, S.Giovanni aTeduccio \\
7 & Miano, Secondigliano, S.Pietro a Patierno \\
8 & Chiaiano, Piscinola-Marianella, Scampia \\
9 & Pianura, Soccavo \\
10 & Bagnoli, Fuorigrotta \\
\hline
\end{tabular}

In the first experiment, we consider the input $x=$ Percentage of inhabitants with less than 5 years old and the output $y=$ Number of public kindergartens. The data extracted are shown in Table 2.

Table 2. The I/O data extracted for the 10 municipalities.

\begin{tabular}{ccc}
\hline Municipality & $\mathbf{x}$ & $\mathbf{y}$ \\
\hline 1 & $4.26 \%$ & 5 \\
2 & $4.77 \%$ & 6 \\
3 & $5.05 \%$ & 6 \\
4 & $4.93 \%$ & 3 \\
5 & $3.80 \%$ & 3 \\
6 & $5.61 \%$ & 9 \\
7 & $5.40 \%$ & 5 \\
8 & $5.35 \%$ & 8 \\
9 & $5.29 \%$ & 6 \\
10 & $4.11 \%$ & 5 \\
\hline
\end{tabular}

The fuzzy partitions are composed by fuzzy numbers given by semi-trapezoidal or triangular fuzzy sets [19]. The first and last fuzzy sets are semi-trapezoidal, and the intermediate fuzzy sets are triangular. The triangular fuzzy numbers are represented with three number, as $A=\left(a_{1}, a_{2}, a_{3}\right)$ and $\mathrm{B}=\left(\mathrm{b}_{1}, \mathrm{~b}_{2}, \mathrm{~b}_{3}\right)$. In Table 3 we show the four fuzzy sets forming the fuzzy partition of the domain $\mathrm{U}_{\mathrm{x}}$.

Table 3. The fuzzy partition for $\mathrm{U}_{\mathrm{x}}$.

\begin{tabular}{cccc}
\hline Label & $\mathbf{a}_{\mathbf{1}}$ & $\mathbf{a}_{\mathbf{2}}$ & $\mathbf{a}_{\mathbf{3}}$ \\
\hline low & 0 & 2 & 4 \\
adequate & 2 & 4 & 5 \\
fair & 4 & 5 & 6 \\
high & 5 & 6 & 8 \\
\hline
\end{tabular}

In Table 4 we show the five fuzzy sets forming the fuzzy partition of the domain $\mathrm{U}_{\mathrm{y}}$. 
Table 4. The fuzzy partition for $\mathrm{U}_{\mathrm{y}}$.

\begin{tabular}{cccc}
\hline Label & $\mathbf{a}_{\mathbf{1}}$ & $\mathbf{a}_{\mathbf{2}}$ & $\mathbf{a}_{\mathbf{3}}$ \\
\hline very low & 0 & 1 & 3 \\
low & 1 & 3 & 4 \\
mean & 3 & 4 & 7 \\
high & 4 & 7 & 10 \\
very high & 7 & 10 & 12 \\
\hline
\end{tabular}

In Figures 2 and 3 we show the graphs of the fuzzy sets of the fuzzy partitions for the domains $U_{x}$ and $U_{y}$, respectively.

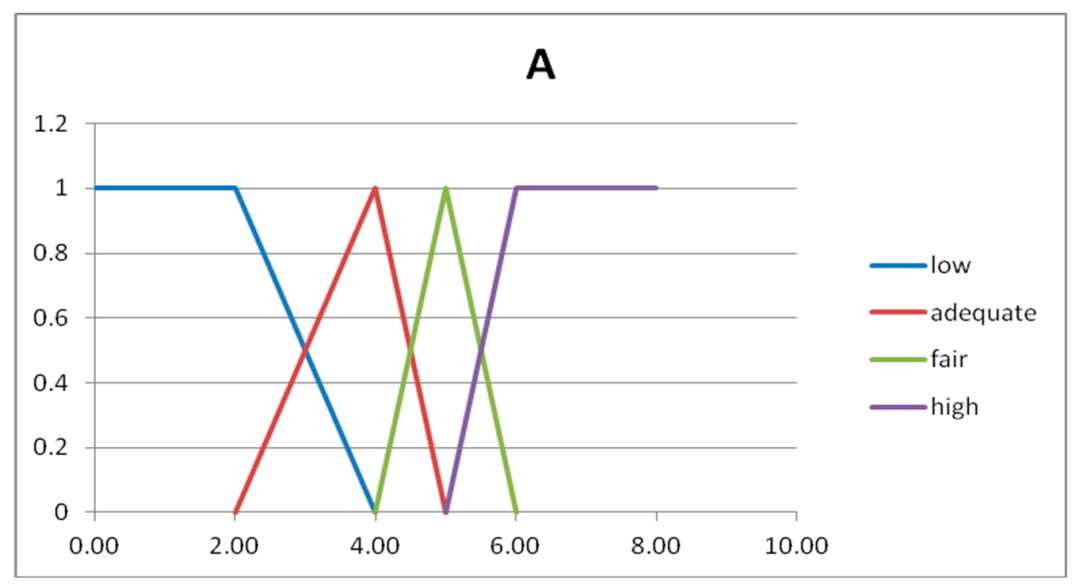

Figure 2. Graph of the fuzzy sets of the fuzzy partition for $U_{x}$.

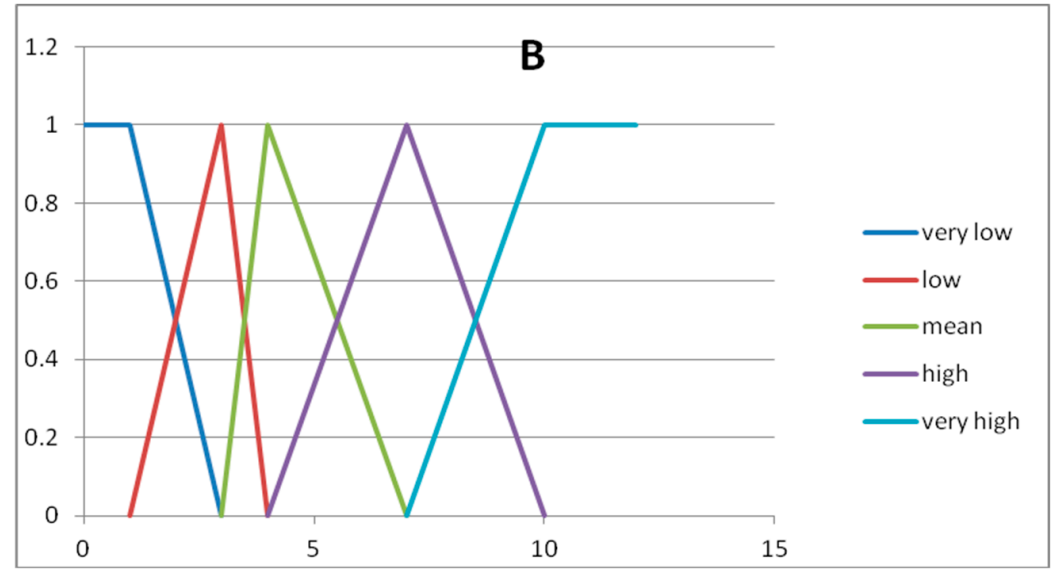

Figure 3. Graph of the fuzzy sets of the fuzzy partition for $U_{y}$.

The expert considers the following rules to be significant:

Rule $1 \rightarrow$ IF A= low THEN B = very low

Rule $2 \rightarrow$ IF $\mathrm{A}=$ adequate THEN B = mean

Rule $3 \rightarrow$ IF A = fair THEN B = high

Then, the index of strength of each fuzzy rule is calculated. Table 5 (resp., Table 6) shows E, H, I, corresponding to the three rules for $\mathrm{p}=1$ (resp., $\mathrm{p}=2$ ). 
Table 5. E, H, I value obtained by setting $\mathrm{p}=1$.

\begin{tabular}{cccc}
\hline \multirow{2}{*}{ Rule } & \multicolumn{3}{c}{$\mathbf{p = 1}$} \\
\cline { 2 - 4 } & $\mathbf{E}$ & $\mathbf{H}$ & $\mathbf{I}$ \\
\hline Rule 1 & 99.00 & 0.00 & 0.99 \\
Rule 2 & 82.50 & 3.68 & 0.79 \\
Rule 3 & 75.78 & 5.76 & 0.70 \\
\hline
\end{tabular}

Table 6. E, H, I value obtained by setting $\mathrm{p}=2$.

\begin{tabular}{cccc}
\hline \multirow{2}{*}{ Rule } & \multicolumn{3}{c}{$\mathbf{p = 1}$} \\
\cline { 2 - 4 } & $\mathbf{E}$ & $\mathbf{H}$ & $\mathbf{I}$ \\
\hline Rule 1 & 95.60 & 0.00 & 0.95 \\
Rule 2 & 75.85 & 4.36 & 0.71 \\
Rule 3 & 64.66 & 6.87 & 0.58 \\
\hline
\end{tabular}

For calibrating the threshold value for the index I, after extracting the data $\mathrm{x}$ and $\mathrm{y}$, the expert analyzes how each fuzzy rule appears consistent with respect to the data, i.e., which the degree of the fuzzy rule is confirmed from the data. He considers Rule 1 completely consistent with the data, and Rule 2 sufficiently consistent; therefore, Rule 3 is not sufficiently consistent with the data. For this reason, we set the threshold value to less or equal to the strength index I calculated for Rule 2. This value is 0.79 for $\mathrm{p}=1$ and 0.71 for $\mathrm{p}=2$. Then we set $\mathrm{p}=2$ and $\mathrm{I}_{\mathrm{th}}=0.7$ in all the experiments.

Below we present the results of the second experiment in which two input variables are considered. The inputs are the following: $x_{1}=$ Percentage of families in residential properties with respect to the total resident families and $x_{2}=$ Percentage of graduates with respect to the total workforce. The output is $\mathrm{y}=$ Unemployment rate.

In Table 7, we show the data extracted for the 10 municipalities.

Table 7. The I/O data extracted for the 10 municipalities.

\begin{tabular}{cccc}
\hline Municipality & $\mathbf{x}_{\mathbf{1}}$ & $\mathbf{x}_{\mathbf{2}}$ & $\mathbf{y}$ \\
\hline 1 & $30.86 \%$ & $60.86 \%$ & 13.46 \\
2 & $13.62 \%$ & $52.52 \%$ & 26.77 \\
3 & $11.58 \%$ & $53.47 \%$ & 26.53 \\
4 & $8.330 \%$ & $48.41 \%$ & 30.34 \\
5 & $29.94 \%$ & $69.54 \%$ & 13.53 \\
6 & $4.410 \%$ & $43.85 \%$ & 36.51 \\
7 & $4.280 \%$ & $36.34 \%$ & 41.52 \\
8 & $5.640 \%$ & $36.21 \%$ & 40.69 \\
9 & $6.880 \%$ & $54.69 \%$ & 31.42 \\
10 & $12.84 \%$ & $62.39 \%$ & 22.76 \\
\hline
\end{tabular}

In Tables 8-10, we show the fuzzy sets forming the fuzzy partitions of the domain $U_{x 1}, U_{x 2}$, $\mathrm{U}_{\mathrm{y}}$, respectively.

Table 8. The fuzzy partition for $U_{x 1}$.

\begin{tabular}{cccc}
\hline Label & $\mathbf{a}_{\mathbf{1}}$ & $\mathbf{a}_{\mathbf{2}}$ & $\mathbf{a}_{\mathbf{3}}$ \\
\hline very low & 0 & 1 & 3 \\
low & 1 & 3 & 4 \\
mean & 3 & 4 & 7 \\
high & 4 & 7 & 10 \\
very high & 7 & 10 & 12 \\
\hline
\end{tabular}


Table 9. The fuzzy partition for $U_{x 2}$.

\begin{tabular}{cccc}
\hline Label & $\mathbf{a}_{\mathbf{1}}$ & $\mathbf{a}_{\mathbf{2}}$ & $\mathbf{a}_{\mathbf{3}}$ \\
\hline low & 0 & 30 & 40 \\
adequate & 30 & 40 & 60 \\
fair & 40 & 60 & 80 \\
high & 60 & 80 & 100 \\
\hline
\end{tabular}

Table 10. The fuzzy partition for $U_{y}$.

\begin{tabular}{cccc}
\hline Label & $\mathbf{a}_{\mathbf{1}}$ & $\mathbf{a}_{\mathbf{2}}$ & $\mathbf{a}_{\mathbf{3}}$ \\
\hline very low & 0 & 10 & 15 \\
low & 10 & 15 & 30 \\
mean & 15 & 30 & 50 \\
high & 30 & 50 & 60 \\
very high & 50 & 60 & 100 \\
\hline
\end{tabular}

In Figures 4-6, we show the graphs of the fuzzy sets of the fuzzy partitions for the domains $U_{x 1}$, $\mathrm{U}_{\mathrm{x} 2}, \mathrm{U}_{\mathrm{y}}$, respectively.

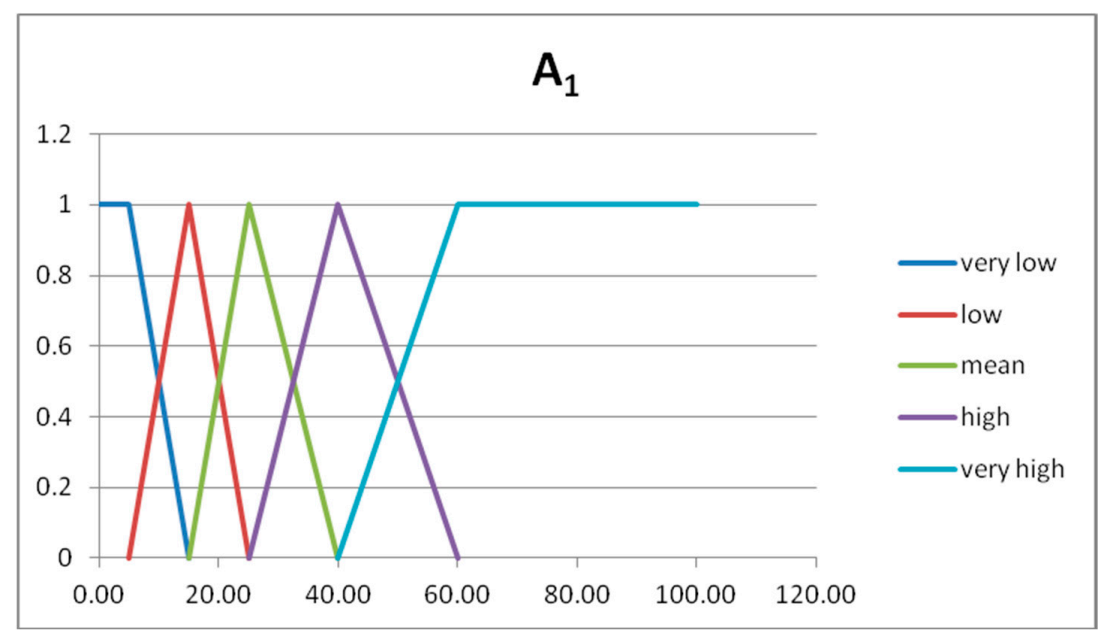

Figure 4. Graph of the fuzzy sets of the fuzzy partition for $U_{x 1}$.

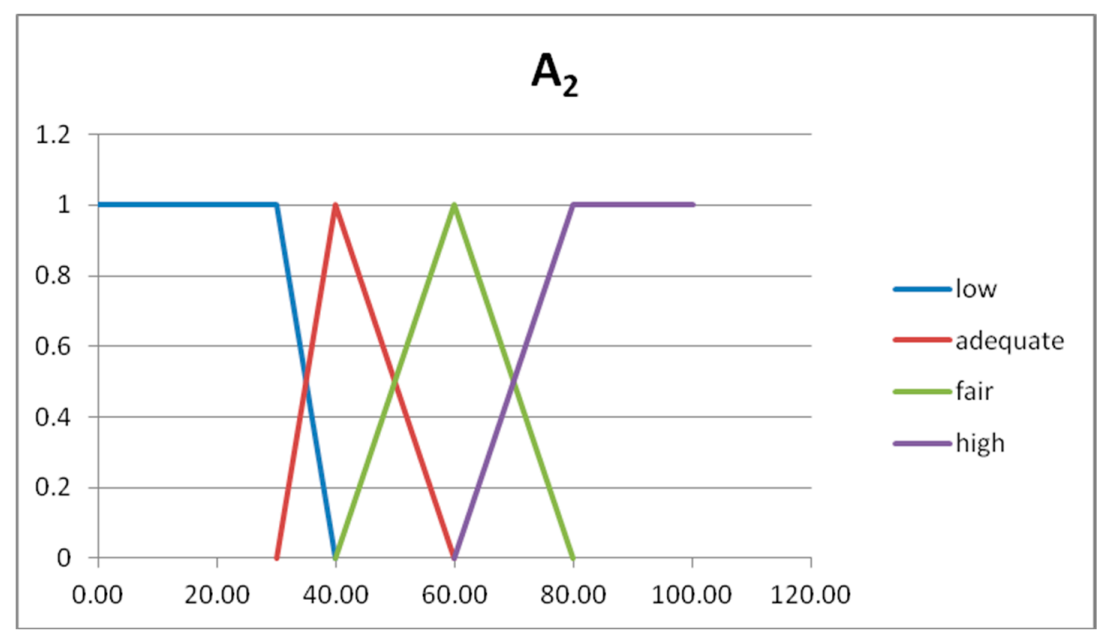

Figure 5. Graph of the fuzzy sets of the fuzzy partition for $U_{x 2}$. 


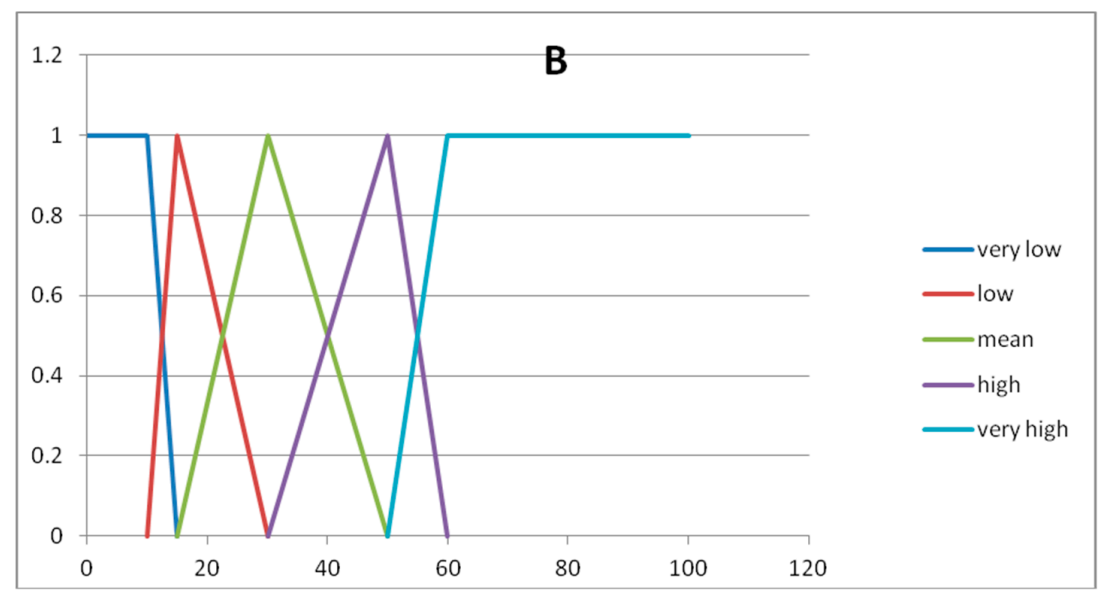

Figure 6. Graph of the fuzzy sets of the fuzzy partition for $U_{y}$.

The expert considers the following fuzzy rules:

Rule $1 \rightarrow$ IF $\mathrm{A}_{1}=$ very low AND $\mathrm{A}_{2}=$ low THEN B = very high

Rule $2 \rightarrow$ IF $\mathrm{A}_{1}=$ low AND $\mathrm{A}_{2}=$ low THEN B $=$ high

Rule $3 \rightarrow$ IF $\mathrm{A}_{1}=$ mean $\mathrm{AND} \mathrm{A}_{2}=$ adequate $\mathrm{THEN} \mathrm{B}=$ mean

Rule $4 \rightarrow$ IF $\mathrm{A}_{1}=$ mean AND $\mathrm{A}_{2}=$ fair THEN B = mean

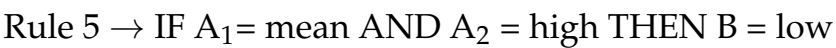

Rule $6 \rightarrow$ IF $\mathrm{A}_{1}=$ high AND $\mathrm{A}_{2}=$ fair THEN B $=$ low

Rule $7 \rightarrow$ IF $\mathrm{A}_{1}=$ high $\mathrm{AND} \mathrm{A}_{2}=$ high THEN $\mathrm{B}=$ very low

Rule $8 \rightarrow$ IF $\mathrm{A}_{1}=$ very high $\mathrm{AND} \mathrm{A}_{2}=$ high THEN $\mathrm{B}=$ very low

In Table 11, we show the value of the index I calculated for any fuzzy rule (column I rule), when $\mathrm{p}=2$. For each pair $\left(\mathrm{A}_{\mathrm{w}}^{(1)}, \mathrm{B}_{\mathrm{z}}\right)$ and $\left(\mathrm{A}_{\mathrm{w}}^{(2)}, \mathrm{B}_{\mathrm{z}}\right)$ in the rule, we show the values of $\mathrm{E}, \mathrm{H}, \mathrm{I}$.

Table 11. Values of the index I obtained for $\mathrm{p}=2$.

\begin{tabular}{|c|c|c|c|c|c|}
\hline \multirow{2}{*}{ Rule } & \multirow{2}{*}{ Pair } & \multicolumn{4}{|c|}{$p=2$} \\
\hline & & E & $\mathbf{H}$ & I & I Rule \\
\hline \multirow{2}{*}{ Rule 1} & $\left(\mathrm{~A}_{1}=\right.$ very low, $\mathrm{B}=$ very high $)$ & 32.00 & 0.00 & 0.32 & \multirow{2}{*}{0.32} \\
\hline & $\left(\mathrm{A}_{2}=\right.$ low, $\mathrm{B}=$ very high $)$ & 84.50 & 0.00 & 0.84 & \\
\hline \multirow{2}{*}{ Rule 2} & $\left(\mathrm{~A}_{1}=\right.$ low, $\mathrm{B}=$ high $)$ & 64.24 & 2.67 & 0.61 & \multirow{2}{*}{0.61} \\
\hline & $\left(\mathrm{A}_{2}=\right.$ low, $\mathrm{B}=$ high $)$ & 88.88 & 0.00 & 0.89 & \\
\hline \multirow{2}{*}{ Rule 3} & $\left(\mathrm{~A}_{1}=\right.$ mean, $\mathrm{B}=$ mean $)$ & 84.65 & 1.20 & 0.83 & \multirow{2}{*}{0.80} \\
\hline & $\left(\mathrm{A}_{2}=\right.$ adequate, $\mathrm{B}=$ mean $)$ & 82.92 & 2.67 & 0.80 & \\
\hline \multirow{2}{*}{ Rule 4} & $\left(\mathrm{~A}_{1}=\right.$ mean, $\mathrm{B}=$ mean $)$ & 95.30 & 0.00 & 0.95 & \multirow{2}{*}{0.72} \\
\hline & $\left(\mathrm{A}_{2}=\right.$ fair, $\mathrm{B}=$ mean $)$ & 76.58 & 5.68 & 0.72 & \\
\hline \multirow{2}{*}{ Rule 5} & $\left(\mathrm{~A}_{1}=\right.$ mean, $\mathrm{B}=$ low $)$ & 88.59 & 2.00 & 0.87 & \multirow{2}{*}{0.87} \\
\hline & $\left(\mathrm{A}_{2}=\right.$ high, $\mathrm{B}=$ low $)$ & 90.81 & 0.00 & 0.91 & \\
\hline \multirow{2}{*}{ Rule 6} & $\left(\mathrm{~A}_{1}=\right.$ high, $\mathrm{B}=$ low $)$ & 90.60 & 2.00 & 0.89 & \multirow{2}{*}{0.89} \\
\hline & $\left(\mathrm{A}_{2}=\right.$ high, $\mathrm{B}=$ low $)$ & 90.81 & 0.00 & 0.91 & \\
\hline \multirow{2}{*}{ Rule 7} & $\left(\mathrm{~A}_{1}=\right.$ high, $\mathrm{B}=$ very low $)$ & 86.68 & 1.85 & 0.85 & \multirow{2}{*}{0.85} \\
\hline & $\left(A_{2}=\right.$ high,$B=$ very low $)$ & 86.20 & 0.00 & 0.86 & \\
\hline \multirow{2}{*}{ Rule 8} & $\left(\mathrm{~A}_{1}=\right.$ very high, $\mathrm{B}=$ very low $)$ & 100.00 & 0.00 & 1.00 & \multirow{2}{*}{0.91} \\
\hline & $\left(\mathrm{A}_{2}=\right.$ high, $\mathrm{B}=$ very low $)$ & 90.81 & 0.00 & 0.91 & \\
\hline
\end{tabular}


The results in Table 11 show that the final indices of the fuzzy rules are greater than the threshold $\mathrm{I}_{\mathrm{th}}=0.7$, except for the fuzzy rules 1 and 2 .

\section{Conclusions}

We present a new method that uses fuzzy energy and fuzzy entropy to evaluate the strength of fuzzy rules set by an expert, with respect to a set of data. We correlate the input and the output data via Equation (5), where $t$ is the Yager $t$-norm, and calculate the corresponding relations which are solutions of (5) with maximum energy and minimum entropy.

After the processes of the creation of the fuzzy partitions of the input and output variable domains, and of the significant fuzzy rule set by the expert, a normalized index of the strength of each fuzzy rule with respect to the data is measured.

If this index is greater than a calibrated threshold, then the fuzzy rule is considered significant with respect to the data. We extend this approach to fuzzy rules in which there are two or more input variables. In this case, we calculate the index of strength separately for each pair of input and output, and we assign a best index of strength to the rule(s) having the minimum value of these indices. The results of some experiments are presented in order to show how our algorithm works inside a fuzzy rule set.

Author Contributions: Conceptualization, F.D.M. and S.S.; Methodology, F.D.M. and S.S.; Software, F.D.M. and S.S.; Investigation, F.D.M. and S.S.; Writing-Original Draft Preparation, F.D.M. and S.S.; Writing-Review \& Editing, F.D.M. and S.S.

Funding: This research received no external funding.

Acknowledgments: This paper was realized under the auspices of INDAM/GCNS (Italy).

Conflicts of Interest: The authors declare no conflict of interest.

\section{References}

1. De Luca, A.; Termini, S. Entropy and energy measures of fuzzy sets. In Advances in Fuzzy Set Theory and Applications; Gupta, M.M., Ragade, R.K., Yager, R.R., Eds.; North-Holland: Amsterdam, The Netherlands, 1979; pp. 321-338.

2. De Luca, A.; Termini, S. A definition of non-probabilistic entropy in the setting of fuzzy sets theory. Inf. Control 1972, 20, 301-312. [CrossRef]

3. Wang, W.-J.; Chiu, C.-H. Entropy and information energy for fuzzy sets. Fuzzy Sets Syst. 1999, 108, 333-339. [CrossRef]

4. Di Nola, A.; Pedrycz, W.; Sessa, S. On measures of fuzziness of solutions of fuzzy relation equations with generalized connectives. J. Math. Anal. Appl. 1985, 106, 443-453. [CrossRef]

5. Di Nola, A.; Pedrycz, W.; Sessa, S. Fuzzy relation equations with LSC and USC T-norms and their Boolean solutions. Stochastica 1987, 11, 151-183.

6. Pedrycz, W. Fuzzy relational equations with generalized connectives and their applications. Fuzzy Sets Syst. 1983, 10, 185-201. [CrossRef]

7. Sanchez, E. Solutions in composite fuzzy relation equations: Application to medical diagnosis in Brouwerian logic. In Fuzzy Automata and Decision Processes; Gupta, M.M., Saridis, G.N., Gaines, B.R., Eds.; North-Holland: Amsterdam, The Netherlands, 1973; pp. 221-234.

8. Yager, R.R. On general class of fuzzy connectives. Fuzzy Sets Syst. 1980, 4, 235-242. [CrossRef]

9. Das, S.; Ghosh, S.; Kar, S.; Pal, M.T. An algorithmic approach for predicting unknown information in incomplete fuzzy soft set. Arab. J. Sci. Eng. 2017, 42, 3563-3571. [CrossRef]

10. Lee, H.-M.; Chen, C.-M.; Chen, J.-M.; Jou, Y.-L. An efficient fuzzy classifier with feature selection based on fuzzy entropy. IEEE Trans. Syst. Man Cybern. Part B Cybern. 2001, 3, 426-432.

11. Matiaško, K.; Boháčik, J.; Levashenko, V.; Kovalík, S. Learning fuzzy rules from fuzzy decision tree. J. Inf. Control Manag. Syst. 2006, 4, 143-154.

12. Zeng, W.; Li, H. Relationship between similarity measure and entropy of interval valued fuzzy sets. Fuzzy Sets Syst. 2006, 157, 1477-1484. [CrossRef] 
13. Zhang, H.; Zhang, W.; Mei, C. Entropy of interval-valued fuzzy sets based on distance and its relationship with similarity measure. Knowl. Based Syst. 2009, 22, 449-454. [CrossRef]

14. Markechová, D.; Riečan, B. Entropy of fuzzy partitions and entropy of fuzzy dynamical systems. Entropy 2016, 18, 19. [CrossRef]

15. Markechová, D.; Riečan, B. Logical entropy of fuzzy dynamical systems. Entropy 2016, 18, 157. [CrossRef]

16. Barchielli, A.; Gregoratti, M.; Toigo, A. measurement uncertainty relations for position and momentum: Relative entropy formulation. Entropy 2017, 19, 301. [CrossRef]

17. Xiao, F. A novel evidence theory and fuzzy preference approach-based multi-sensor data fusion technique for fault diagnosis. Sensors 2017, 17, 2504. [CrossRef] [PubMed]

18. Sarwar, M.; Akram, M. Certain algorithms for computing strength of competition in bipolar fuzzy graphs. Int. J. Uncertain. Fuzzy Knowl. Based Syst. 2017, 25, 877-896. [CrossRef]

19. Tang, H.-C. Decomposition and intersection of two fuzzy numbers for fuzzy preference relations. Symmetry 2017, 9, 228. [CrossRef]

(C) 2018 by the authors. Licensee MDPI, Basel, Switzerland. This article is an open access article distributed under the terms and conditions of the Creative Commons Attribution (CC BY) license (http:/ / creativecommons.org/licenses/by/4.0/). 